\title{
Key Issues of Green Construction Management and Project Cost Control in the New Era
}

\author{
Guoan Wei \\ Henan Technical College of Construction, Zhengzhou, Henan, China \\ *Corresponding Author.
}

\begin{abstract}
:
Green building is the inevitable trend of the development of the construction industry. One of the key links to realize green building is green construction management. The poor economy of traditional construction hinders the smooth promotion of green construction in the construction industry. This paper mainly from the green building and green construction two concepts of related content research. Through the analysis and discussion of the main principles of project cost management in green construction, this paper briefly expounds some implementation measures of project cost management in green construction. This paper deeply discusses the current situation of green construction project cost management, and puts forward relevant improvement countermeasures. The experimental results show that: construction enterprises should make innovative thinking on construction management and bring green construction into project management. This can provide impetus for the sustainable development of the construction industry.
\end{abstract}

Keywords: Green Building, Construction Economy, Green Construction, Project Cost Management.

\section{INTRODUCTION}

BIM takes the relevant information data of construction projects as the basis of building model, and simulates the real information of buildings through digital information virtual technology [1]. It is not a simple integration of digital information, but as a means of digital information application, using digital model to plan, design, build and operate the whole life cycle of buildings.

After the introduction of this technology into China and its successful implementation, both at the national and local levels and all parties involved in the construction project attach great importance to this technology, and there are more than 100 application points developed for the whole life cycle of buildings [2-3]. As a brand-new management tool, BIM Technology subverts the traditional architectural design mode, engineering cost mode and construction management mode [4]. Through the digital expression of various physical and functional characteristics in the whole life cycle of the project, it can obtain the sharing of knowledge resources and provide the basis for various decisions. With the rapid development of economic globalization and technology demand, BIM Technology will be more widely used in various fields of construction engineering. 


\section{GREEN CONSTRUCTION AND BUILDING INFORMATION MODEL (BIM)}

\subsection{Building information model (BIM)}

People in the industry generally agree that the article "comparing pommes and naranjas" published by American architect Jerry laiserin in - 2002 is the beginning of "BIM" being widely used as a professional term in the engineering construction industry [5-7].

\section{1) Definition of BIM}

The full name of the English abbreviation "BIM" can be regarded as "building information mode" or "building information modeling", that is, "BIM" has two meanings: building information model and its modeling process.

BIM is based on three-dimensional digital technology to collect all kinds of relevant data in construction projects, which is a form of displaying the functional characteristics and building entities of engineering projects through digitization. BIM is a perfect information model, which can provide real-time engineering data that can be automatically calculated, queried, combined and split when the construction project participants need it. BIM has a single engineering data source, which can solve the consistency and global sharing problems between engineering data [8]. At the same time, it is also a visual database, which is a realtime sharing data platform for the project.

2) BIM software introduction

The practical application of BIM Technology in engineering project is not only realized by a BIM software or a certain type of BIM software, but also by mutual integration and cooperation between BIM software [9-10].

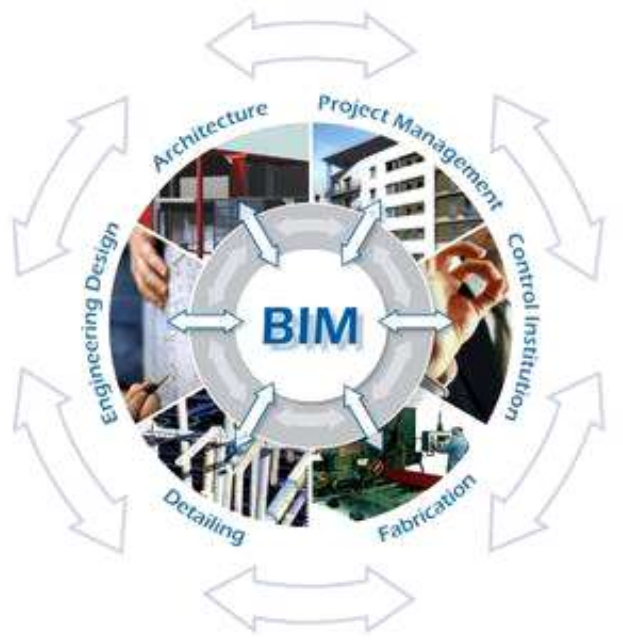

Fig 1: BIM software type

In BIM software, the most important and basic software is "BIM core modeling software", which is used to create BIM basic model.

\section{3) Green BIM}

Green development is an eternal goal of the development of modern construction industry. The successful application of BIM Technology in the process of construction management, the realization of the advantage allocation and reasonable layout of building resources will have a profound impact on green construction management.

The combination of BIM and green building forms the concept of green BIM, which McGraw Hill 
Construction defines as "aiming at achieving sustainability at the project level and improving building energy efficiency targets with BIM tools".

The introduction of green BIM in the development of BIM in China will make Chinese construction enterprises realize the value of BIM more comprehensively, promote the development of BIM in China, and will also help to enhance the market competitiveness of Chinese construction enterprises and effectively curb the serious waste of resources.

Through the research of the enterprises using green BIM Technology in the United States, it is shown that in the early stage of BIM practice, BIM is often used as a modeling tool, and it is only applied to visual design, collision detection, improving the output efficiency of engineering drawings, etc., but it is lack of further analysis through model data. However, this phenomenon will be changed with the introduction of green BIM concept and the strengthening of practice.

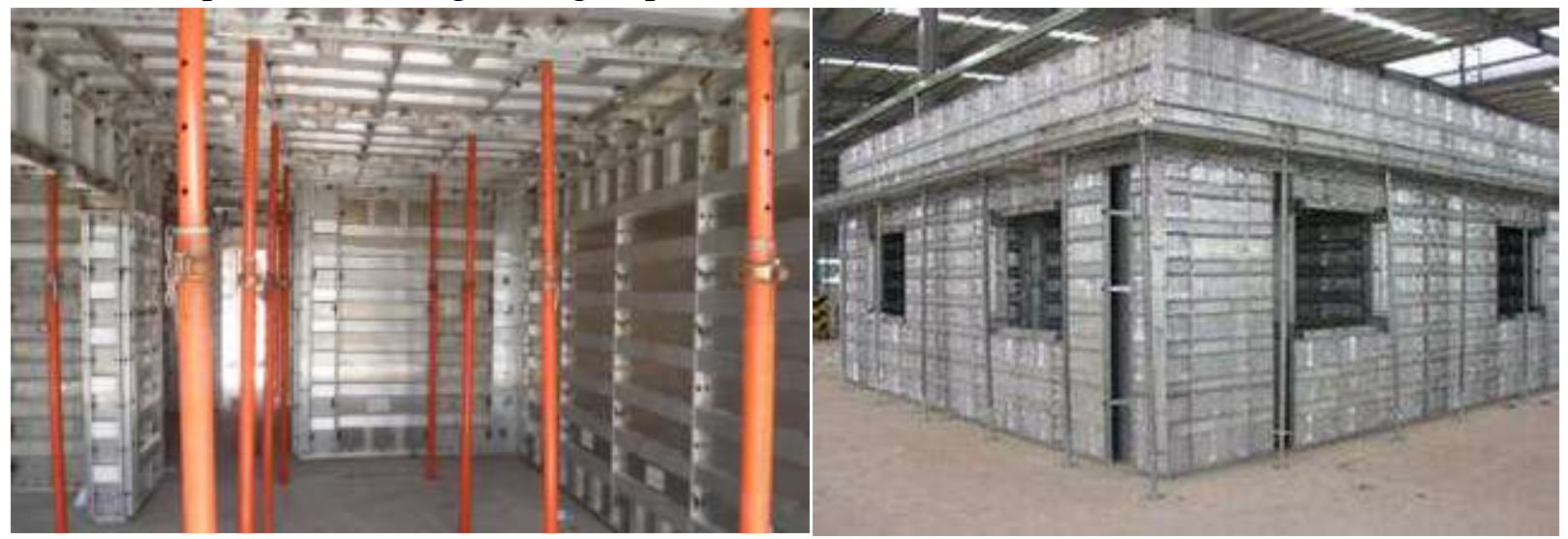

Fig 2: Basic usage of BIM

(Comparison between enterprises using green BIM Technology and enterprises not using green BIM Technology)

"Results in front" is the value embodiment of BIM Technology in green construction, so that project managers have already known how to do it before they really implement it, so as to achieve the goal of "four sections and one environmental protection". How to save water, land, materials and energy, how to save and protect labor costs, and to what extent these problems can be implemented can be found through a digital information model.

\section{GREEN CONSTRUCTION INFORMATION MANAGEMENT SYSTEM BASED ON BIM TECHNOLOGY}

\subsection{Construction of green construction information management system based on BIM Technology}

The information management system of green construction based on BIM Technology includes management objectives, contents, methods and processes. With BIM as the technical means, combined with the concept of green construction management, from the perspective of the comprehensive interests of Party $\mathrm{A}$, the needs of society and environment, and the economic benefits of construction enterprises, the value of green construction production is identified, the implementation links of green construction production are analyzed and optimized, and the unity of social, environmental and economic benefits is realized. The construction process of green construction information management system based on BIM Technology is as follows: 


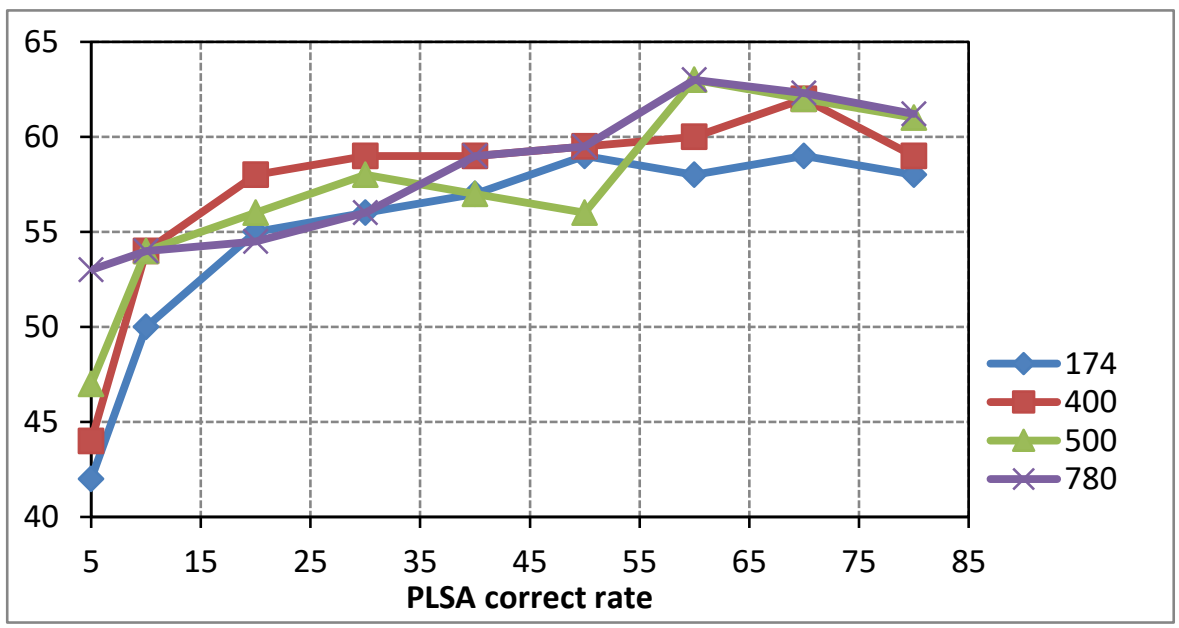

Fig 3: The comparison results of BIM application

To build a green construction information management system based on BIM Technology, we should not only make full use of the advantages of BIM Technology, but also integrate the concept of green construction to achieve the goal of green construction management

\subsection{Information management method of green construction based on BIM Technology}

1) Application of BIM Technology in water saving and water resources utilization

The application of BIM Technology in water saving is mainly reflected in the simulation of site drainage design; the design and planning of each floor drain location; the design of rainwater, wastewater and other non-traditional water collection and recycling.

BIM Technology can be used to simulate the process of construction water use. For example, when the foundation pit is in the dewatering stage and the foundation trench is not backfilled, the groundwater is used as the water for concrete maintenance. The underground water is used to spray on the site to reduce dust and wash the concrete tank car. It can also simulate the situation of the construction site, according to the situation of the construction site, prepare a detailed temporary water scheme for the construction site, so that the water supply network of the construction site can be designed and arranged according to the water consumption, adopt reasonable pipe diameter and simple pipeline, and effectively reduce the leakage of the pipe network and water appliances.

Use the software of Revit to arrange the temporary water pipe network on the site, establish the water recovery system, recycle the water and rainwater on the site, and use it to wash the vehicles in and out of the site, use the water in the toilet, and keep the temporary road clean. The construction site implements the concept of water saving, and some of them are cured with circulating water. The maintenance water is sprayed on the surface of the structural layer with professional tools, so as to save water. The reclaimed water in the on-site collecting pool is used as the water for spraying pavement, greening irrigation and concrete maintenance at the construction site, and the municipal water supply can be used only when the reclaimed water in the pool is insufficient. Reasonable planning and utilization of rainwater and foundation pit dewatering, improve the utilization rate of non-traditional water conservancy.

2) Application of BIM Technology in energy saving and energy utilization

BIM Technology to promote green construction, reduce pollution, save energy, reduce resource consumption and waste is the direction and purpose of future building development. Energy saving is reflected in the green environmental protection in two aspects: one is to help the building form the recycling 
of natural light resources, water circulation and wind energy flow, and scientifically select the most suitable construction form according to different orientation, location and function. The other is to reduce the "carbon" emissions of buildings. During construction, it is necessary to make full use of information technology to shorten the construction period; during operation and maintenance, it can not only meet the use needs of various functions, but also ensure the minimum and optimal resource consumption.

3) Application of BIM Technology in environmental protection

BIM Technology can be used to simulate the discharge and placement of construction site waste, so as to achieve the purpose of emission reduction and environmental protection. The specific methods are as follows:

(1) The BIM model is used to prepare a special scheme to identify, evaluate and control the "three wastes" discharge of wastewater, waste and waste residue on the construction site. Special personnel and funds are arranged to formulate special measures to reduce the "three wastes" discharge on the construction site.

(2) According to the BIM model, a sedimentation tank is set up for the construction wastewater in the construction area, which is reused or discharged in accordance with the regulations after sedimentation treatment. The slurry and other wastewater that cannot be treated simply are centralized and handed over to a professional company for treatment. Oil separation tank and septic tank are set in the living area to collect and clean up the wastewater in the living area.

(3) BIM model is used to reasonably arrange the location and use time of noise sources, and effective noise protection measures are adopted to reduce noise emission and meet the requirements of environmental noise emission standards at the construction site boundary.

\section{APPLICATION OF BIM TECHNOLOGY IN GREEN CONSTRUCTION OF BUILDING ENGINEERING}

4.1 Analysis of key and difficult points of the project

(1) Prestressed structural beam engineering

In order to meet the functional requirements of large span and large opening of the lobby, the prestressed concrete beam members constructed by post tensioning method are designed at the top of the first floor central hall. Because the tensioning equipment is too large and heavy to be directly installed on the scaffold, the secondary construction technology of constructing prestressed concrete beam after the main body is completed is adopted.

(2) Mechanical and electrical engineering

The mechanical and electrical installation of the project involves many specialties, such as water supply and drainage, fire protection, HVAC, electrical bridge and so on. Due to the large number of special-shaped structural members and high requirements for floor height control, it is difficult to coordinate the construction of mechanical and electrical equipment and various professional pipelines.

(3) Curtain wall engineering

The North facade of the fifth to eighth floors of the project is an aluminum clad steel frame hidden frame glass curtain wall composed of three tangent arcs, the surface of which also needs to be installed with aluminum alloy sunshade blinds, the other three sides are staggered overlapped with the glass curtain wall, and there is an arc glass curtain wall on the South top floor. The project uses the arc-shaped assembled glass curtain wall as the facade decoration, with complex design, many engineering components, complicated installation process, difficult positioning and turning of the arc-shaped glass surface, and many cross 
operations.

\subsection{Application of green construction based on BIM Technology}

1) Deepening design and construction of curved glass curtain wall

The curtain wall construction of the project has the characteristics of complex design drawings, complicated installation procedures, difficult positioning and construction of arc glass surface, many structural components, and many cross operations. Through virtual installation of complex curtain wall nodes, effective measures are taken to make up for the design defects.

The preliminary survey found that there was a large deviation in the size of concrete structural members during the construction of civil engineering specialty, the maximum deviation reached $22 \mathrm{~mm}$, which was in conflict with the finished surface of curtain wall. After communicating with the design unit, the curtain wall skin was adjusted, and the finished surface of curtain wall was shifted outward by $100 \mathrm{~mm}$. Because the curve offset is larger than the original finished surface, the glass finished surface at the intersection of the two sides will also change. Through the modeling of the software of Revit, the glass skin is segmented in the model, and several surfaces are extracted separately. It is found that the left and right sides of the surface are basically straight lines, and the arch height of the upper and lower arc sides is less than or equal to $3 \mathrm{~mm}$. Combined with the experience of similar projects in the past, it is feasible to use flat glass instead of the original curved glass with smaller arch height of upper and lower arc sides. At the same time, each cut glass is numbered separately, and then the flat glass is arranged according to the unique number of each glass to compound the original model and optimize the curtain wall skin design.

Through communication and consultation with the design unit, BIM Technology is used to help it improve the curtain wall design, optimize the material cutting and installation process, greatly shorten the glass processing cycle, reduce the material waste to the greatest extent, and save the construction period.

2) Noise pollution source control

According to the requirements of the national standard "environmental noise emission standard for construction site boundary", the noise emission limits of construction site boundary are 70dB in the daytime and $55 \mathrm{~dB}$ at night.

The project adopts the method of reducing the noise of the sound source or installing a muffler at the sound source to achieve the limit requirements.

BIM is used to reasonably arrange the noise source (the noise source of the project is mainly mixer), which is not only convenient for the construction needs, but also far away from the office area, living area and surrounding houses of the construction site as far as possible. At the same time, $4.8 * 3.5$ steel pipe is used to set up the protective shed structure. In addition, a closed enclosure is set around the protective shed. The enclosure is made of fireproof and sound insulation iron splint, and openings are set at the upper hopper and outlet to wrap the noise source.

The field measurement shows that the noise emission meets the standard requirements, and the noise emission at the construction site is effectively controlled.

\section{CONCLUSION}

By analyzing the advantages of BIM Technology in green construction management, the idea and technical route of BIM application are formulated, and the green construction information management system based on BIM Technology is constructed with management objectives, management methods and 
management process as elements. The establishment of the system, in addition to making the project in the construction process to complete the traditional construction cost saving, shorten the construction period, improve the quality of the three goals, but also can help the project smoothly achieve the ultimate goal of "four sections and one environmental protection" green construction. The successful application of BIM Technology in the implementation of green construction is not to increase the project cost and increase the difficulty of construction, but an indispensable technical means to achieve fine construction, which has broad development prospects and positive promotion significance.

\section{ACKNOWLEDGEMENTS}

This research was supported by Training Program for Young Backbone Teachers in Higher Vocational Schools in Henan Province (Grant No. 2019GZGG073).

\section{REFERENCES}

[1]Papaphilippou, C., et al. "Surface aluminum alloy formation by electrodeposition from alkali chloride melts and by laser techniques." Acta Metallurgica Et Materialia 40.7(1992):1691-1698.

[2] Rath, Surya Kumar Dube, Girija Prasad. "Application of Valsalva manoeuvre to facilitate resection of intradiploic arachnoid cyst." Indian Journal of Anaesthesia 58.4(2014):490-1.

[3] Lin, C. H., et al. "Self-consolidating concrete columns under concentric compression." Aci Structural Journal 105.4(2008):425-432.

[4] Kim, Gwang Hee, H. M. Song, and Y. S. Shin. "A Case Study on the Use of Aluminum Forms in Nuclear Power Plant Construction." Advanced Materials Research 919-921.919-921(2014):296-299.

[5] Marsh, Cedric. "Fifty Years of Aluminum in Construction." Journal of the Construction Division 101(1975):583592.

[6] Xie, Hui, et al. "Lithium Distribution in Aluminum-Free Cubic Li7La3Zr2O12." ChemInform 42.44(2011):35873589.

[7] Tam, Vivian W. Y., and C. M. Tam. "Evaluations of existing waste recycling methods: A Hong Kong study." Building \& Environment 41.12(2006):1649-1660.

[8] Defraeye, Thijs, et al. "Forced-convective cooling of citrus fruit: Cooling conditions and energy consumption in relation to package design." Journal of Food Engineering 121(2014):118-127.

[9] Berrada, A., K. Loudiyi, and I. Zorkani. "Sizing and economic analysis of gravity storage." Journal of Renewable \& Sustainable Energy 8.2(2016):824-829.

[10] Cheng, Lijuan, and V. M. Karbhari. "Design approach for a FRP structural formwork based steel-free modular bridge system." Structural Engineering \& Mechanics 24.5(2006):561-584. 